\title{
Theoretical Calculation of Stiffness of Composite Laminated Beam with T-Section
}

\author{
Hu Ming-yong, Zhang Xiang-ming, Zheng Bo \\ College of Science, Naval Univ. Engineering, \\ Wuhan 430033, \\ Peoples Republic of China \\ shuai_humingyong@163.com
}

\begin{abstract}
Based on the constitutive equation and deformation equation, the total stiffness matrix of laminated composite beam with $T$-section are built up by using the relation of 3D stress-stain transformation. Then calculation methods of the axial and bending stiffness of laminated composite beam with T-section are derived. Axial and bending stiffness of laminated composite beam with $T$-section are calculated under the uniformly distributed load or concentrated force with various boundary condition. A comparison between analytical calculation results and ANSYS calculation results shows good agreement. The results show that this method is reliable. And easy to apply in the initial design of composite hull. The research makes foundation for theoretically calculate laminated composite beam with arbitrary cross-section.
\end{abstract}

Keywords- laminated composite beam; T-section; stiffness; $3 D$ stress-strain transformation

\section{INTRODUCTION}

References [1, 2] are related to analysis of composite laminate beam. But the analysis methods are too complex to be applied in engineering design of composite laminate structure. For the former, the calculation can be degraded from the theories of laminated plates. The stiffener of various shapes (L-type, T-type and hat shaped, etc) is used to stiffen the stiffness and strength of composite laminate beams. It is difficult to determine the stiffness characteristics and structural response through resolution. Most scholars adopt the theory of composite laminate beams or approximate equations [3-5] to calculate the mechanical response. Now the finite element software is widely applied in design and calculation [6-8] of composite laminate beams. But for modeling and calculation of large composite models, the calculation periods of finite element is too long. Also, it needs a lot of design parameters, making it difficult to perform flexible parameterized study. The theoretic calculation method is more convenient and flexible for preliminary design of composite structures.

\section{THE TOTAL STIFFNESS MATRICES OF COMPOSITE LAMINATE BEAM WITH T-SECTION}

In Fig. 1-Fig. 2, we establish a local coordinate system $\left(x_{1}, y_{1}, z_{1}\right)$ and $\left(x_{2}, y_{2}, z_{2}\right)$ on the middle surface of the web laminate and base lamiate. Assuming that (1-2-3) is the coordinate direction of fiber material that is laid inside $\left(x_{2}^{\prime}, y_{2}^{\prime}\right)$. The angle-ply $\beta$ is defined as follows: the positive

Project supported by national natural science foundation of china (Nos.51479206); Project supported by natural science foundation of Hubei Province (Nos.2015CFC868) direction of $x_{2}^{\prime}$ will coincide with the fiber direction after counterclockwise rotating $\beta$ around axis $z_{2}^{\prime}$.

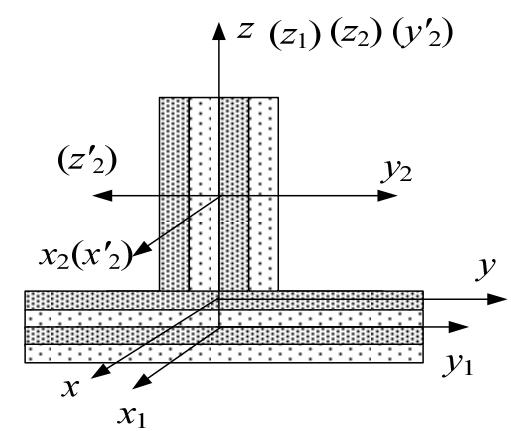

Fig. 1. Sketch of beam with T-section.

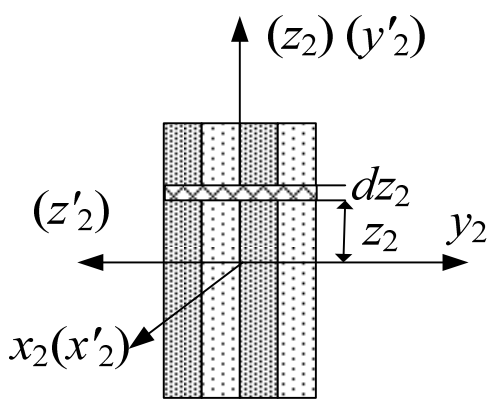

Fig. 2. Sketch of web laminate section.

The following equations can be obtained:

$$
\begin{aligned}
& {[\sigma]_{1-2-3}^{k}=\left[T_{\sigma}(\theta)\right]_{x_{2}}\left[T_{\sigma}(\beta)\right]_{z_{2}^{\prime}}[\sigma]_{x_{2}-y_{2}-z_{2}}^{k}} \\
& {[\varepsilon]_{1-2-3}^{k}=\left[T_{\varepsilon}(\theta)\right]_{x_{2}}\left[T_{\varepsilon}(\beta)\right]_{z_{2}^{\prime}}[\varepsilon]_{1-2-3}^{k}}
\end{aligned}
$$

where,

$$
[\sigma]_{1-2-3}^{k}=[Q]^{k}[\varepsilon]_{1-2-3}^{k}
$$


$[Q]^{k}$ is called as reduced stiffness matrices of $k^{\text {th }}$ layer and the subscripts 1 and 2 refer to the properties along the fiber and transverse to the fiber respectively. Substituting (2) into (1) results in:

where,

$$
\begin{aligned}
& {\left[\hat{Q}_{x_{2}-y_{2}}\right]^{k}=\left[T_{\sigma}(\beta)\right]_{z_{2}^{\prime}}^{-1}\left[T_{\sigma}(\theta)\right]_{x_{2}}^{-1}[Q]^{k}\left[T_{\varepsilon}(\theta)\right]_{x_{2}}\left[T_{\varepsilon}(\beta)\right]_{z_{2}^{\prime}}=\left[\begin{array}{lll}
\hat{Q}_{11} & \hat{Q}_{12} & \hat{Q}_{16} \\
\hat{Q}_{12} & \hat{Q}_{22} & \hat{Q}_{26} \\
\hat{Q}_{16} & \hat{Q}_{26} & \hat{Q}_{66}
\end{array}\right]^{k}} \\
& \hat{Q}_{11}=Q_{11} \cos ^{4} \beta+2\left(Q_{12} \cos ^{2} \theta+2 \cos ^{2} \theta Q_{66}\right) \sin ^{2} \beta \cos ^{2} \beta+Q_{22} \sin ^{4} \beta \\
& \hat{Q}_{12}=\sin ^{2} \beta \cos ^{2} \beta\left(Q_{11}+\cos ^{4} \theta Q_{22}-4 \cos ^{2} \theta Q_{66}\right)+\left(\cos ^{4} \beta+\sin ^{4} \beta\right) \cos ^{2} \theta Q_{12} \\
& \hat{Q}_{22}=Q_{11} \sin ^{4} \beta+2 \sin ^{2} \beta \cos ^{2} \beta\left(\cos ^{2} \theta Q_{12}+2 \cos ^{2} \theta Q_{66}\right)+Q_{22} \cos ^{4} \beta \cos ^{4} \theta \\
& \hat{Q}_{16}=\sin \beta \cos ^{3} \beta\left(Q_{11}-\cos ^{2} \theta Q_{12}-2 \cos ^{2} \theta Q_{66}\right)+\sin ^{3} \beta \cos \beta\left(Q_{12} \cos ^{2} \theta-Q_{22} \cos ^{4} \theta+2 \cos ^{2} \theta Q_{66}\right) \\
& \hat{Q}_{26}=\sin ^{3} \beta \cos \beta\left(Q_{11}-\cos ^{2} \theta Q_{12}-2 \cos ^{2} \theta Q_{66}\right)+\sin \beta \cos ^{3} \beta\left(\cos ^{2} \theta Q_{12}-\cos ^{4} \theta Q_{22}+2 \cos ^{2} \theta Q_{66}\right) \\
& \hat{Q}_{66}=\sin ^{2} \beta \cos ^{2} \beta\left(Q_{11}+\cos ^{4} \theta Q_{22}-2 \cos ^{2} \theta Q_{12}-2 \cos ^{2} \theta Q_{66}\right)+\left(\cos ^{4} \beta+\sin ^{4} \beta\right) Q_{66}
\end{aligned}
$$

The reference axis for the T-section is initially selected as the mid-height of the web laminate. The stiffness matrices of web laminate respect to own mid-plane can be obtained.

$$
\begin{aligned}
& {[\bar{A}]_{w}=\int_{-\frac{h}{2}}^{\frac{h}{2}}\left[A^{\prime}\right] d z_{2}=h\left[A^{\prime}\right]} \\
& {[\bar{B}]_{w}=\int_{-\frac{h}{2}}^{\frac{h}{2}}\left(\left[B^{\prime}\right]-z_{2}\left[A^{\prime}\right]\right) d z_{2}=\left[B^{\prime}\right] h} \\
& {[\bar{D}]_{w}=\int_{-\frac{h}{2}}^{\frac{h}{2}}\left(\left[D^{\prime}\right]-2 z_{2}\left[B^{\prime}\right]+z_{2}^{2}\left[A^{\prime}\right]\right) d z_{2}=\left[D^{\prime}\right] h+\frac{h^{3}}{12}\left[A^{\prime}\right]}
\end{aligned}
$$

The total stiffness matrices of the laminate beam can be obtained by multiplying the width of each laminate.

\section{AXIAL AND BENDING STIFFNESS OF LAMINATED COMPOSITE BEAM WITH T-SECTION}

The following equations can be obtained:

$$
\left\{\begin{array}{c}
\varepsilon^{0} \\
k
\end{array}\right\}=\left[\begin{array}{cc}
A & B \\
B & D
\end{array}\right]_{6 \times 6}^{-1}\left\{\begin{array}{l}
N \\
M
\end{array}\right\}
$$

$\varepsilon_{x}^{0}, \varepsilon_{y}^{0}$ and $\gamma_{x y}^{0}$ are the mid-plane strains. $\kappa_{x}, \kappa_{y}$ and $\kappa_{x y}$ are the mid-plane curvatures. $N x, N y$ and $N x y$ are the resultant forces per unit width of the laminate. $M x, M x y$, and $M x$ are the resultant moments per unit width of the laminate.

Currently, most laminated composite beams with T-section are narrow beams. As for them, axial distortion caused by axial strain is due to possion ratio and can be ignored. Therefore, only two components need to be taken into account i.e. $N x$ and
$M x$; other components can be ignored. (6) can be converted into:

$$
\left\{\begin{array}{l}
\bar{\varepsilon}_{x}^{0} \\
\bar{k}_{x}
\end{array}\right\}=\left[\begin{array}{ll}
\bar{a}_{11} & \bar{b}_{11} \\
\bar{b}_{11} & \bar{d}_{11}
\end{array}\right]\left\{\begin{array}{l}
\bar{N}_{x} \\
\bar{M}_{x}
\end{array}\right\}
$$

Where $\bar{a}_{11}, \bar{b}_{11}, \bar{d}_{11}$ is the total flexibility matrix coefficient of the laminated composite beam with T-section. According to the definition of neutral axis, the load component $\bar{N}_{x}$ will not cause the change of curvature $\bar{k}_{x}$, and the load moment $\bar{M}_{x}$ will not cause the change of $\bar{\varepsilon}_{x}^{0}$. When the moment $\bar{M}_{x}$ acting on the axial direction is only considered, (7) can be expressed as following:

$$
\left\{\begin{array}{l}
\bar{\varepsilon}_{x}^{0}=\bar{b}_{11} \bar{M}_{x} \\
\bar{k}_{x}=\bar{d}_{11} \bar{M}_{x}
\end{array}\right.
$$

When the structure is subject to the axial deformation, $\bar{k}_{x}=0$. According to the definition of the axial stiffness, the axial stiffness of the laminated composite beam with T-section is calculated:

$$
(E A)_{\text {beam }}=\frac{\bar{d}_{11}}{\bar{a}_{11} \bar{d}_{11}-\bar{b}_{11}^{2}}
$$

Similarly, when the structure is subject to pure bending, $\bar{\varepsilon}_{x}^{0}=0$. According to the definition of the bending stiffness, the bending stiffness of the laminated composite beam with Tsection is calculated as following: 


$$
(E I)_{\text {beam }}=\frac{\bar{a}_{11}}{\bar{a}_{11} \bar{d}_{11}-\bar{b}_{11}^{2}}
$$

\section{NUMERICAL CALCULATION}

The length of beam is $0.3 \mathrm{~m}$. There are 10 layers in base laminate, the length is $50.8 \mathrm{~mm}$. There are 8 layers in web laminate, the heigth is $25.4 \mathrm{~mm}$. The thickness of each layer is $0.125 \mathrm{~mm}$. The single-layer laminate is laid with epoxy carbon fiber composite materials. The parameters are as follows: $\mathrm{E} 1=121 \mathrm{Gpa}, \mathrm{E} 2=8.6 \mathrm{Gpa}, \mathrm{G} 12=4.7 \mathrm{Gpa}, \mu_{12}=0.27$. The layup of laminated composite T-section are as following: (1) base laminate: $45^{\circ} /-45^{\circ} /-45^{\circ} / 45^{\circ} / 0^{\circ} / 0^{\circ} / 45^{\circ} /-45^{\circ} /-45^{\circ} / 45^{\circ}$; web laminate: $45^{\circ} /-45^{\circ} /-45^{\circ} / 45^{\circ} / 45^{\circ} /-45^{\circ} /-45^{\circ} / 45^{\circ}$. (2)base laminate: $90^{\circ} / 0^{\circ} / 90^{\circ} / 0^{\circ} / 90^{\circ} / 90^{\circ} / 0^{\circ} / 90^{\circ} / 0^{\circ} / 90^{\circ}$; web laminate: $45^{\circ} /-45^{\circ} /-45^{\circ} / 45^{\circ} / 45^{\circ} /-45^{\circ} /-45^{\circ} / 45^{\circ}$. (3) base laminate: $90^{\circ} / 0^{\circ} / 90^{\circ} / 0 \%$ \% $90 \% 90^{\circ} / 0 \% 90^{\circ} / 0^{\circ} / 90^{\circ}$; web laminate: $90^{\circ} / 0 \% 90 \% 0 \% 0^{\circ} / 90^{\circ} / 0^{\circ} / 90^{\circ}$. The results calculation are as seen in Fig. 3-Fig. 5 and Table I. The theoretical calculation results matches the finite element calculation, which means that the model applied, formula derived and programs written in this paper are correct and reliable. Furthermore, the layup of fiber is effect on the stiffness of laminated composite T-section. The $90^{\circ} / 0^{\circ}$ layup is better than the $45^{\circ} /-45^{\circ}$ layup. The axial stiffness of laminated composite $\mathrm{T}$-section is better than the bending stiffness of laminated composite T-section.

TABLE I. DEFORMATION OF COMPOSITE BEAM WITH T-SECTION

\begin{tabular}{|c|c|c|c|c|c|c|c|c|c|}
\hline \multirow{3}{*}{ layup } & \multicolumn{6}{|c|}{ The max bending deformation } & \multirow{2}{*}{\multicolumn{3}{|c|}{$\begin{array}{c}\text { Axial deformation } \\
\text { Axial tensile force } N_{c}=1000 N\end{array}$}} \\
\hline & \multicolumn{3}{|c|}{$\begin{array}{l}\text { Concentrated force } F=300 N \\
\text { (Simply supported) }\end{array}$} & \multicolumn{3}{|c|}{$\begin{array}{c}\text { Evenly-distributed load } q=1000 \mathrm{~N} / \mathrm{m} \\
\text { (clamped end) }\end{array}$} & & & \\
\hline & $\begin{array}{c}\text { Present } \\
\text { Method }(\mathrm{mm})\end{array}$ & $\begin{array}{l}\text { FEM Result } \\
(\mathrm{mm})\end{array}$ & Difference & $\begin{array}{l}\text { Present Method } \\
(\mathrm{mm})\end{array}$ & $\begin{array}{l}\text { FEM Result } \\
\qquad(\mathrm{mm})\end{array}$ & Difference & $\begin{array}{l}\text { Present Method } \\
\qquad(\mathrm{mm})\end{array}$ & $\begin{array}{l}\text { FEM Result } \\
\qquad(\mathrm{mm})\end{array}$ & Difference \\
\hline (1) & 2.063 & 2.044 & $1 \%$ & 0.258 & 0.254 & $1.5 \%$ & 0.103 & 0.102 & $1 \%$ \\
\hline (2) & 1.447 & 1.431 & $1.2 \%$ & 0.185 & 0.181 & $1.6 \%$ & 0.072 & 0.071 & $1.4 \%$ \\
\hline (3) & 1.230 & 1.226 & $1.7 \%$ & 0.164 & 0.161 & $2.1 \%$ & 0.052 & 0.051 & $1.9 \%$ \\
\hline
\end{tabular}

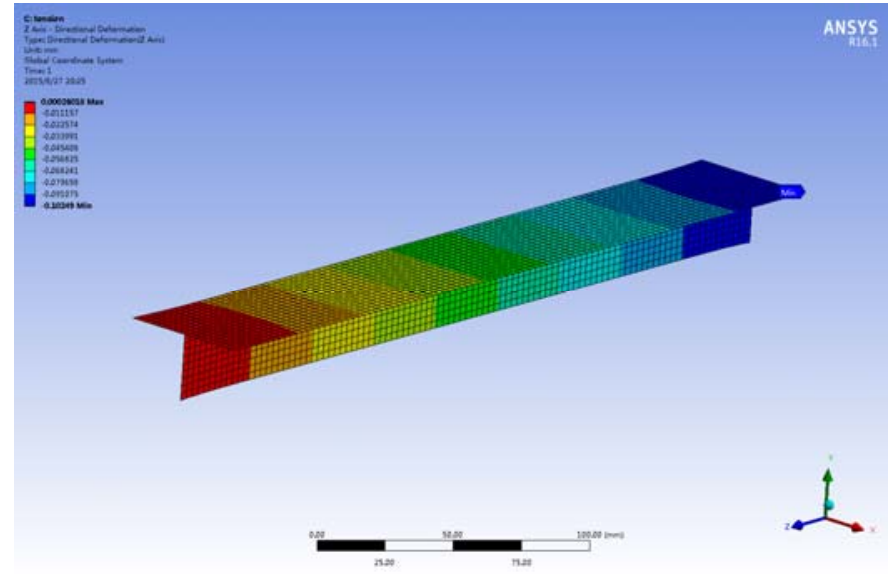

Fig. 3. Axial displacement

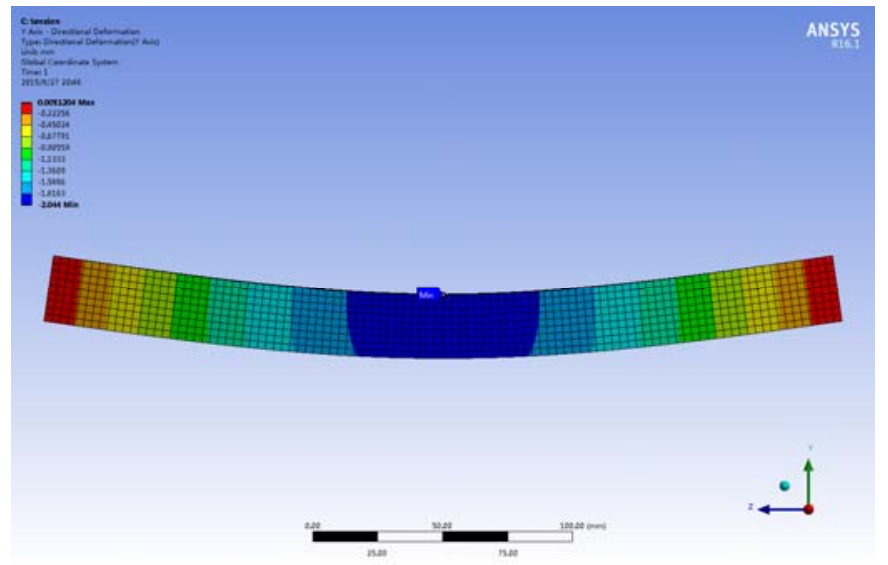

Fig. 4. Deformation due to concentrated force.

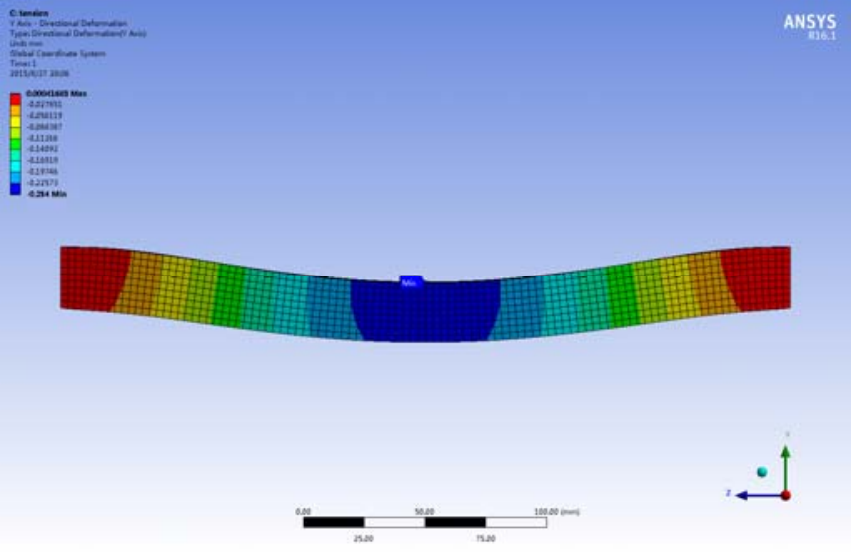

Fig. 5. Deformation due to uniform load.

\section{CONCLUSION}

Based on the constitutive equation, deformation equation and parallel axis theorem of stiffness matrices, the total stiffness matrices of composite laminate beam with T-section was built up by using the relation of 3D stress-stain transformation. Then the analytical calculation equations of the axial and bending stiffness of composite laminate beam with $\mathrm{T}$-section were derived. The axial and bending stiffness of composite laminate beam with $\mathrm{T}$-section were calculated under the uniformly distributed load or concentrated force with various boundary conditions. A comparison between analytical calculation results and ANSYS calculation results showed good agreement. Thus, the methods and the calculation equations derived in this paper are reliable. This paper lays a basis for initial design and optimization of the composite laminate beam with T-section and provides theoretical support for theoretical calculation of composite laminate beams with 
arbitrary shape section. The work in the paper has high engineering value in initial design of composite structures.

\section{REFERENCES}

[1] A.M. Skudra, A.A. Kruklinsh, F.Y. Bulavs, and M.R. Gurvich, Structural Analysis of Composite Beam Systems, Technomic, Lancaster, PA. 1991.

[2] L.P. Kollar, and G.S. Springer, Chapter $6 \& 7$ in Mechanics of Composite Structures, Cambridge University Press, UK, 2003.

[3] Z.P. Guo, and J.Q. Gong, "A dynamic analysis of stiffened composite plates", Acta Mater. Compos. Sinica,vol. 7, no. 3, pp. 75-80, 1990.

[4] A. Madhujit, "Finite element buckling analysis of stiffened plate". Compos. Struct. vol. 34, pp. 795-803, 1990.

[5] Y.P. Wu, X.J. Wang, "A solution for laminated box beams under bending loads using the principle of comp-plementray energy", Compos. Struct. vol. 79, no. 3, pp. 376-380, 2007.

[6] Z.Y. Cai, W.Y. Tang, N.Z. Chen, and S.K. Zhang, "Ultimate strength analysis of composite laminated ship panels", J. Ship Mech. vol. 13, no. 1, pp. 72-81, 2009.

[7] F.A. Sadck, and S.A. Jawfik, "A finite clement model for the analysis of stiffened laminated plates", Comput. Sturct. vol. 75, pp. 369-383, 2000.

[8] W.G. Jiang, and L.H. John, "Analysis of composite laminate beams using coupling cross-section finite element method", Appl. Math. Mech. vol. 27 , no. 16, pp. 1709-1718, 2006. 